\title{
Ethnobotanical study of indigenous knowledge on medicinal plant use by traditional healers in Oshikoto region, Namibia
}

\author{
Ahmad Cheikhyoussef ${ }^{* *}$, Martin Shapi ${ }^{2}$, Kenneth Matengu ${ }^{2}$, Hina Mu Ashekele ${ }^{1}$
}

\begin{abstract}
Background: The objective of this study was to establish a regional profile of the indigenous knowledge system (IKS) for medicinal plant use and cultural practices associated with the healing process of these plants by traditional healers in the Oshikoto region, Namibia.

Methods: An ethnobotanical survey was undertaken to collect information from traditional healers during September and October 2008. Data was collected through the use of questionnaires and personal interviews during field trips in the ten constituencies of the Oshikoto region. A total of 47 respondents were interviewed with most of them aged 66 and above.

Results: The traditional healers in Oshikoto region use 61 medicinal plant species that belong to 25 families for the treatment of various diseases and disorders with the highest number of species being used for mental diseases followed by skin infection and external injuries. Trees ( 28 species) were found to be the most used plants followed by herbs (15 species), shrubs (10 species) and climbers (4 species). The average of the informant consensus factor $\left(F_{I C}\right)$ value for all ailment categories was 0.75. High $F_{I C}$ values were obtained for Pergularia daemia, and Tragia okanyua, which were reported to treat weakness and dizziness problems, snake bite, swelling and cardiovascular problems indicating that these species traditionally used to treat these ailments are worth examining for bioactive compounds.
\end{abstract}

Conclusions: The traditional healers in Oshikoto possess rich ethno-pharmacological knowledge. This study allows for identifying many high value medicinal plant species, indicating high potential for economic development through sustainable collection of these medicinal plants.

\section{Background}

Traditional healers are found in most societies. They are often part of a local community, culture and tradition, and continue to have high social standing in many places, exerting influence on local health practices; it is therefore worthwhile to explore the possibilities of engaging them in primary health care and training them accordingly [1]. Most African people still rely heavily on traditional medicine; traditional healers are often the first and last line of defense against most diseases such as headaches, coughs, diarrhoea, wound healing and skin diseases [2]. One advantage in preferring traditional medicine is that

\footnotetext{
* Correspondence: acheikhyoussef@gmail.com

'Science, Technology and Innovation Division, Multidisciplinary Research

Centre- University of Namibia, Private Bag 13301, Windhoek, Namibia

Full list of author information is available at the end of the article
}

traditional healers are found within a short distance, are familiar with the patient's culture and the environment and the costs associated with treatments are negligible [3]. They work on body and mind together to help cure an illness. Traditional medical knowledge of medicinal plants and their use by indigenous healers are not only useful for conservation of cultural traditions and biodiversity but also for community healthcare and drug development in the present and future [4]. Since the beginning of this Century, there has been an increasing interest in the study of medicinal plants and their traditional use in different parts of the world [5-8].

There are about 2400 traditional medical practitioners in Namibia who are registered with the National Eagle Traditional Healers Association (NETHA), but the actual number practicing could be higher [9].

\section{C) Biomed Central}


Approximately 200 Southern African plant species are available in Windhoek, which are mainly imported by traditional healers from other countries. However, the number of local plants used is found to be high, primarily originating from Kavango, Caprivi and other northern regions in Namibia. The traditional medical practitioners reported that 53 plant species were in demand for medicinal trade in Windhoek [9]. Some of the traditional medical practitioners encountered came from the Democratic Republic of Congo, Malawi, Tanzania, Zambia and Zimbabwe [10]. One study reported on traditional healing in Katutura, Windhoek; but did not report details such as species name of the actual plants used. The study mainly concentrated on the traditional healing practices, beliefs, witchcraft and human behavior [11]. The database of plants that occur in the Oshikoto region supplied by National Herbarium of Namibia (WIND) [12] contains 753 species. Cross-checking this list with the SEPASAL (Survey of Economic Plants for Arid and Semi-Arid Lands) database (http://www.kew.org/sepasalweb/sepaweb) revealed that 274 (36.4\%) of these plants are used for medicinal purposes [10].

The documentation of the traditional medicinal plants used by the traditional healers in Oshikoto region is limited compared to the extent of the variety of cultures and the diversity of plants of the region. Furthermore, the majority of these studies are focused only on interviewing traditional healers [13] and listing the plants for food and medicinal use [14] without any detailed ethnobotanical study on the medicinal plant in the region. The present study was conducted in Oshikoto region and to the best of our knowledge; this is the first report on the medicinal plant use by the local traditional healers. The purpose of this study is to assess traditional medicinal plant knowledge specifically with regard to the traditional healer's demographic characteristics such as: gender, age, source of income etc., and to document the knowledge and the uses of medicinal plants used by the traditional healers in Oshikoto region, which is a part of an initiative to document baseline data for future pharmacological and phytochemical studies.

\section{Methods}

Area

The Oshikoto region was selected on the basis that it is inhabited by people from different ethnic groups: the San, Owambo, Damara/Nama, and Ova Herero. It was chosen as a pilot site because it could provide data useful for design of proper data collection instruments for a country-wide baseline study (Figure 1).

\section{Data Collection}

Ethnobotanical knowledge and practice within any culture vary by geographical origin, residence, ethnicity, religion, age, and gender [15]. The biographic characteristics of the respondents in this study include: gender, age of respondents when first starting to practice traditional healing; occupational status and sources of income. This study mainly focused on the use of indigenous medicinal plants by traditional healers. No plant samples were collected. Forty seven respondents with a traditional knowledge of useful medicinal plants, mostly either native born or had been living in the region for long time were interviewed. The research team comprised of two groups; group A covered Oniipa, Onyaanya, Onayena, Olukonda and Omuntele constituencies during September 2008, while group B covered Okankolo, Engodi, Genius, Omuthiya and Tsumeb constituencies during October 2008. Each research team reported to the councilor of the constituency first before they could start with data collection. The councilor himself or somebody else recommended by the councilor led the research teams to the respective healers. Questionnaires designed to the respondents (traditional healers) about medicinal plants knowledge were mainly focused on common local name, knowledge about past and present use, mode of preparation, parts of the plants used, the methods of their preparation and administration, procurement method, place of collection and habitats, threats and conservation status, date/season of collection and types of treated diseases with these medicinal plants.

\section{Data analysis}

Informant Consensus Factor ( $F_{\text {IC }}$ )

The informant or respondent consensus factor $\left(\mathrm{F}_{\mathrm{IC}}\right)$ was calculated to estimate user variability of medicinal plants $[16,17] . F_{I C}$ values range from 0.00 to 1.00 . High $F_{I C}$ values are obtained when only one or a few plant species are reported to be used by a high proportion of informants to treat a particular ailment, whereas low $F_{I C}$ values indicate that informants disagree over which plant to use [16]. High $F_{I C}$ values can thus be used to pinpoint particularly interesting species for the search of bioactive compounds [17]. $\mathrm{F}_{\mathrm{IC}}$ is calculated using the following formula $[16,17]$ :

$$
\mathrm{F}_{\mathrm{IC}}=N_{u r}-N_{t} /\left(N_{u r}-1\right)
$$

Where $N_{u r}$ is the number of individual plant use reports for a particular illness category, and $N_{t}$ is the total number of species used by all informants for this illness category.

\section{The fidelity level (FL)}

The fidelity level (FL), the percentage of informants claiming the use of a certain plant for the same major purpose, was calculated for the most frequently reported 


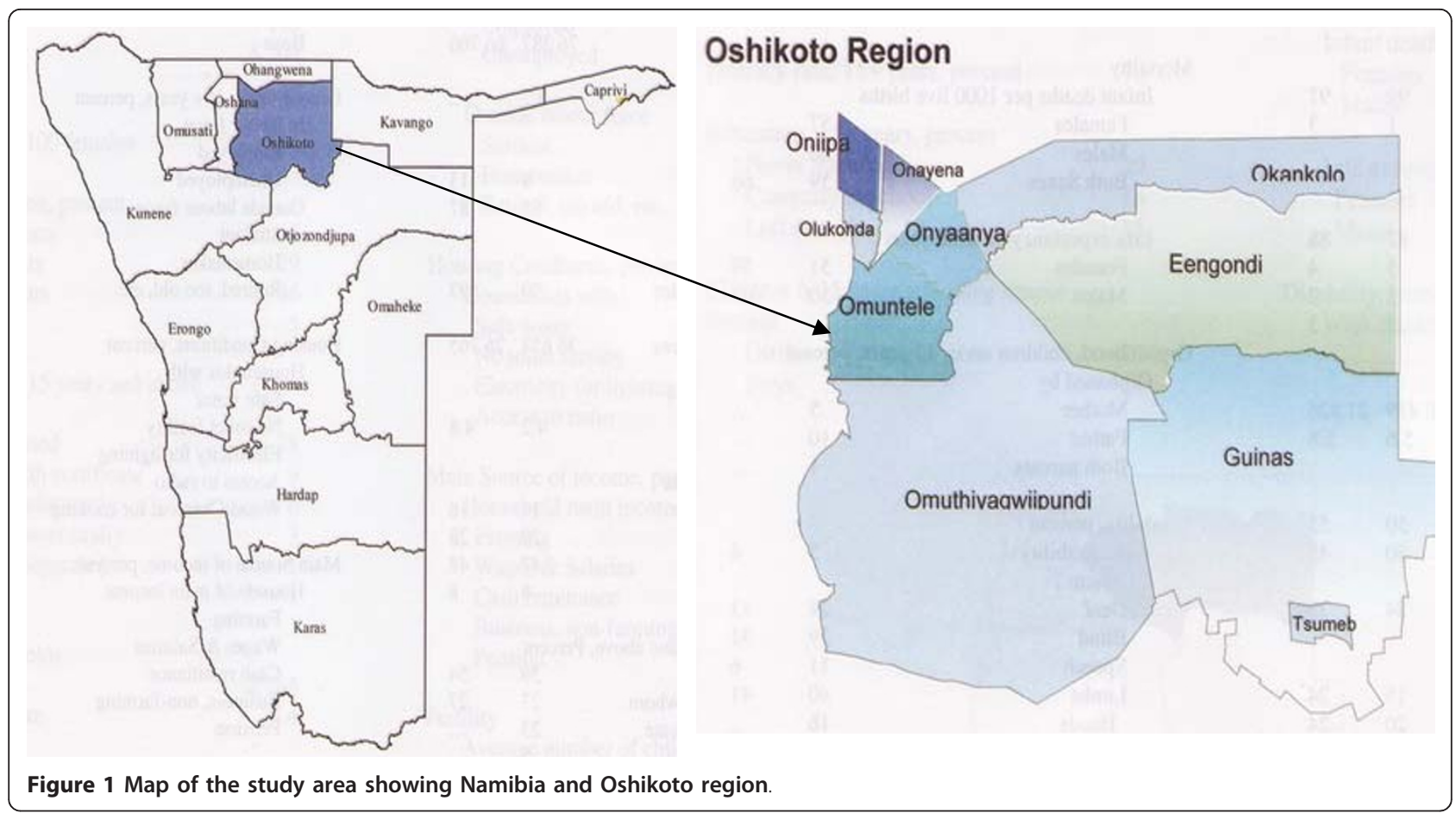

diseases or ailments as following:

$$
\mathrm{FL}(\%)=N p / N \times 100
$$

Where $N p$ is the number of informants that claim a use of a plant species to treat a particular disease, and $N$ is the number of informants that use the plants as a medicine to treat any given disease $[6,18,19]$. Prior to the calculation of FL, reported ailments were grouped into major disease categories following the approach of Heinrich et al. [16]. Generally; plants which are used in some repetitive fashion are more likely to be biologically active [20].

\section{Results and discussion IK and Gender}

Generally, traditional healing is a gender-based practice; although in some communities both men and women perform this practice [21]. It was found that among 47 respondents interviewed, $70 \%$ were women healers compared to only $30 \%$ of men. Women often consider traditional healers first for the treatment of infertility, whereas men's first option is frequent remarriage [22]. Problems related to women fertility are in many cases treated by the women healers though to lesser extent male healers also treat it. However, in some societies such as Kavango and Caprivi the situation is different of which men dominate the sector. The source of the medicinal plants knowledge is the main factor for the difference in knowledge of medicinal plants between women and men, and among respondents [19]. The women learn from their mothers or fathers through routine observations while their fathers' teach the man, in addition to routine observations, since the traditional knowledge in the family or community is passed from male parent to his first-born son [23].

\section{IK and Age}

Indigenous knowledge (IK) is acquired through time in which it takes for the traditional healers to acquire the indigenous knowledge [21]. Most of the people who were known to have substantive knowledge and were practicing, were mostly older than 66 years of age (Figure 2). Bearing in mind the fact that IKS is passed on from one generation to another over time, Figure 3 indicates that less than $20 \%$ of the respondents became healers when they were teenagers and less than $20 \%$ when they were in their thirties.

\section{IK, occupation and source of income}

The traditional healing is widely acknowledged as an occupation in Namibia. This study indicates that $58 \%$ of the respondents regarded themselves as subsistence farmers. Although these particular respondents use medicinal plants to treat ailments, they do not necessarily see themselves as practitioners of a profession/occupation. Twenty eight percent confirmed that they are traditional medicinal practitioners, while four and two percent reported to be pensioners and headman, respectively. It is evident that $37 \%$ and $34 \%$ of the respondents 


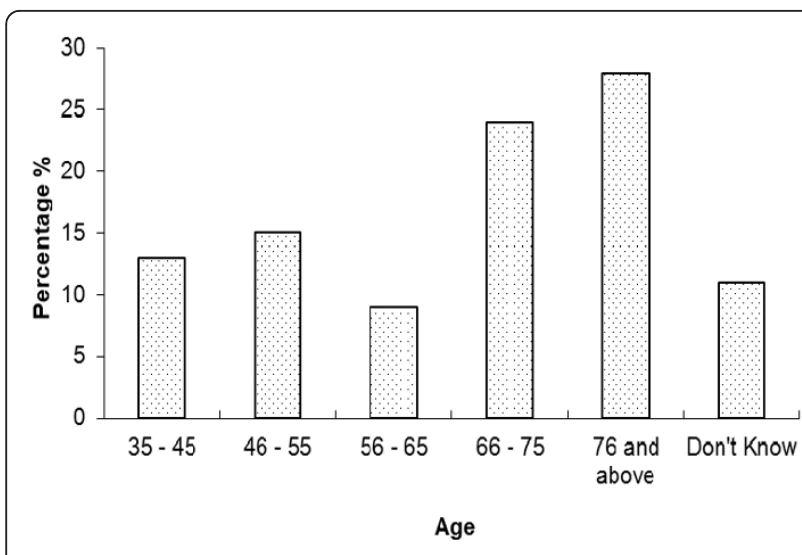

Figure 2 Percentage of healers by age category in Oshikoto, Namibia.

indicated that farming and pension, respectively; are their main sources of income. However, slightly more than $20 \%$ indicated that use of medicinal plants is their main source of income (Figure 4). This shows that a certain proportion of people do make a living from using medicinal plants hence the need to promote it. According to the World Health Organization (WHO), an estimated 3.5 billion people in the developing world depend on medicinal plants as part of their primary health care [24]. Also according to the WHO; $80 \%$ of the world's people depend on traditional medicine for their primary healthcare needs [1]. There are considerable economic benefits in the development of indigenous medicines and in the use of medicinal plants for the treatment of various diseases [25].

\section{IK and mentorships}

Generally in many cases skills and knowledge are usually transferred from grandparents to their grandchildren

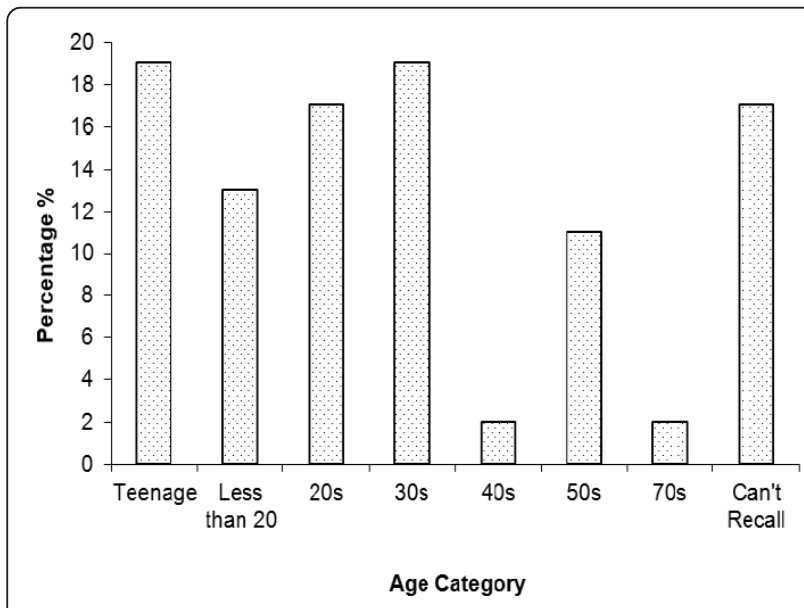

Figure 3 Age when the healers started healing in Oshikoto, Namibia.

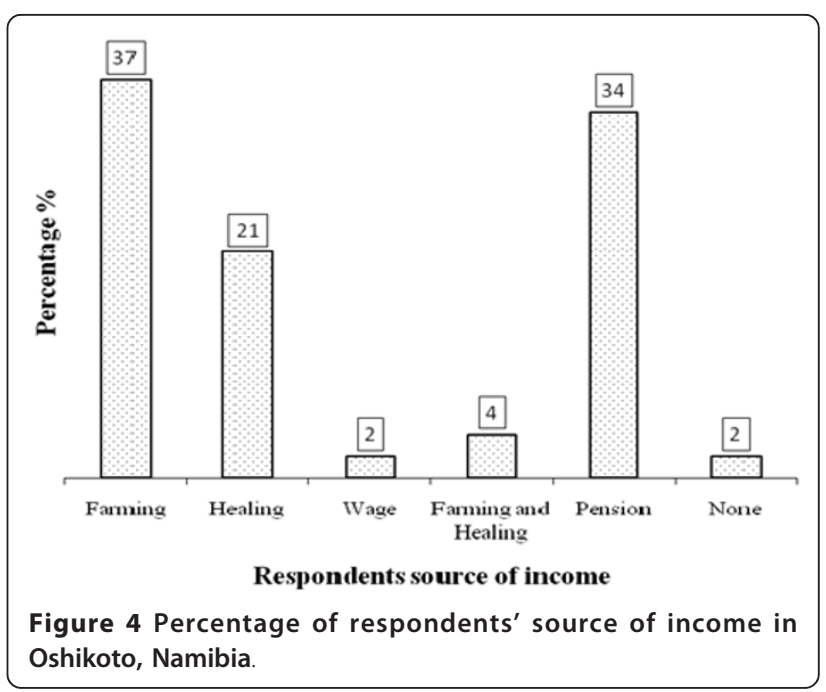

[21]. It is common practice for grandchildren to accompany their grandparents during the medicinal plants collection and during the processes of treating patients. Through these interactions, these children become interested and may be motivated to also practice this profession. Nevertheless, in this study Figure 5 shows that a big number of the respondents indicated that they became healers through another healer, an indication that some form of initiation takes place. The information collected does not detail how exactly this interaction is initiated and the form it takes. Moreover, we do not know what circumstances may have persuaded the healer and the recruited healer to interact. However, 8 respondents indicated that they became healers because their grandmothers were healers, while 6 respondents said that they were healers because their grandfathers were healers also. Seven respondents claimed to have become healers through their grandparents without specifying whether it was their grandmother or grandfather. If one combined the number of

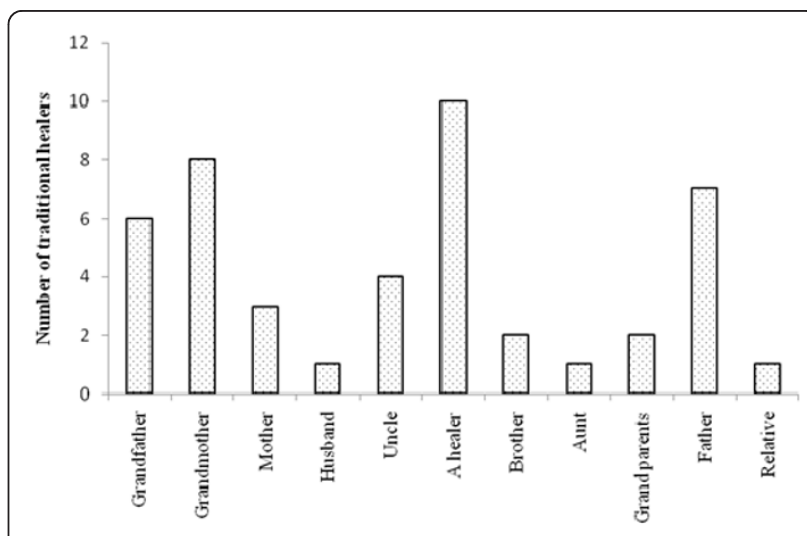

Figure 5 various people who played a mentorship role in passing IKS in Oshikoto, Namibia. 
the respondents who indicated that they became healers through grandfather, grandmother and grandparents mentorship, then it qualifies the African assertion that usually, traditional healing is mainly passed from grandparents to grandchildren because of the close interaction between grandparents and grandchildren as compared to his or her own children.

\section{Rituals for Practicing as Healer}

It is generally believed that to become an acclaimed healer one has to go through the traditional ritual that will allow you to practice as a qualified healer. This process is called lusha or okutetwa in Oshiwambo language [21]. The survey in this study shows that $75 \%$ of the respondents indicated that they went through that process (lusha or okutetwa) before they became traditional healers. This is a sign that signifies the importance of indigenous knowledge in the sense that the community tends to believe that once someone goes through that ritual she or he can be trusted as someone who knows his or her work well. Some applications noted in some areas of Namibia were not compatible with western medical tradition, as local traditional healers have a different understanding of how certain diseases are caused. This is largely because traditional healing is a very complex issue involving rituals and spiritual aspects, far more than simply the use of plants $[11,26]$.

\section{Traditional Healing and Mentorship}

In cases where people indicated that they were mentored, the study sought to establish whether the respondents knew the whereabouts of their mentors. The findings in Figure 6 show that over 45\% of the respondents did not know where their mentors were and 38\% indicated that their mentors had passed away long time ago. This is no surprise since the majority of the respondents were 66 years and above. Only less than $10 \%$ of

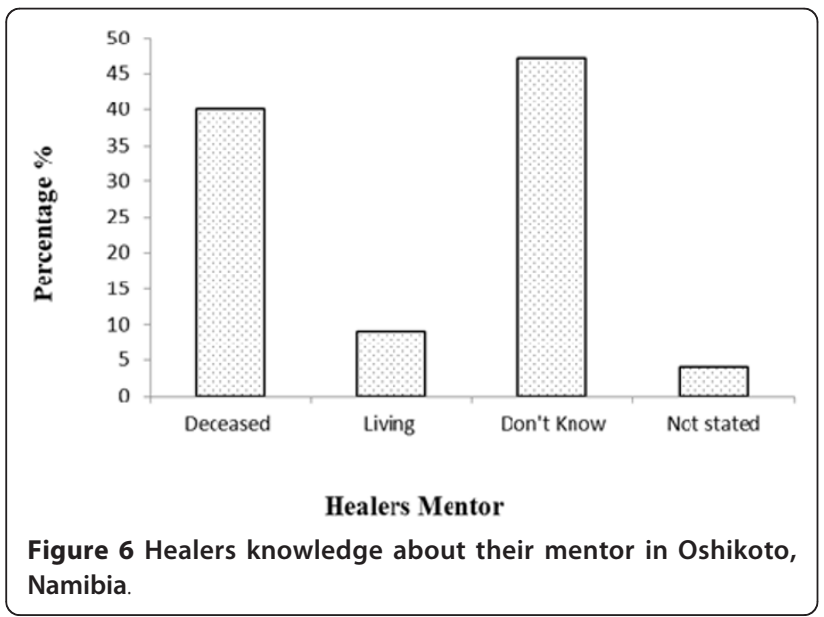

the respondents indicated that their mentors were still alive. The low number of the respondent who indicated that their mentors were living, points to the importance of recording and documenting the IK on one hand and on the other hand, it is indicative of fading participation by the youth in IK. Thus, it can be suggested in the future studies that most of the respondents would not be younger than 30 years of age.

\section{Types of diseases treated}

The traditional healing system in Oshikoto region is well established. Forty seven respondents reported 61 medicinal plants that are used to treat 43 types of ailments and diseases in both human and animal (Table 1). Several common diseases such as leg pains, back pains, chicken pox, ear infection, gonorrhoea, syphilis, stroke, diarrhoea, wound healing and skin diseases were reported to be among the illnesses that traditional healers can treat. This result is in agreement with Busia [27] who reported on the common ailments in Africa such as headaches or coughs are considered to be diseases with natural causes and hence their symptoms are treated at the household level. Various studies have reported on the indigenous use of medicinal plants in the treatment of oral diseases [28] wound healing and skin diseases [29] gastro-intestinal disorders [30]. Many of the remedies which are prescribed by traditional healers can be considered as general health tonics, used to treat weakness and unspecified ailments. Interestingly, there are specific mixtures of different medicinal plants that are often used to treat problems of the stomach, back, kidneys, bladder and other minor ailments [31]. The respondents reported that some types of ailments or diseases can be recovered after one day of treatment such as high fever, sun burns, and ear infection, on the other side some ailments take up to one year like: herpes and bilharzia (Table 1). Table 1 summarizes the ailments and IKS plant-based medicinal plants therapies in Oshikoto region.

\section{Plant parts used and mode of preparation}

Different parts of medicinal plants are used as medicine by the traditional healers (Figure 7). Among the different plant parts, the roots are most frequently used for the treatment of diseases followed by leaves, whole plant parts, barks, tubers, seeds, fruits, pods, and stems. This result is in agreement with studies of Leffers [26] who presents and describes 238 plant species occurring in the eastern Tsumkwe Constituency, Nyae Nyae Conservancy in Namibia between 1999 and 2002 by one of the oldest and most fascinating cultures on the African continent, the Jul'hoansi. They use a wide range of different plants and plant parts, but plant roots play a significantly important role [26]. The result is also in agreement with 
Table 1 Medicinal plants used to cure various ailments in Oshikoto region, Namibia

\begin{tabular}{|c|c|c|c|c|}
\hline Scientific name & Family & Local name & Ailment & Time of recovery \\
\hline \multirow[t]{2}{*}{ Acacia ataxacantha } & Fabaceae & Mukoro & Headache & 3 days \\
\hline & & & Pneumonia & 3-5 days \\
\hline Acacia mellifera & Fabaceae & Okadilanghono & Snake bite & $1-2$ days \\
\hline \multirow[t]{2}{*}{ Acanthosycios naudiniana } & Cucurbitaceae & Ruputwi & Mental illnesses & 2 - 3 days, up to 16 months \\
\hline & & & Inflammation & Vary \\
\hline Aloe littorals & Asphodelaceae & Endombo & Bilharzia & 1 year \\
\hline Asparagus nelsii & Asparagaceae & Okawekamuthithi & Eczema & 1 - 7 day \\
\hline Asparagus virgatus & Asparagaceae & Runkwanana & Mental illnesses & 2 - 3 days, up to 16 months \\
\hline Baphia massaiensis & Fabaceae & Omulyambambi & Fertility/impotent & 1 day \\
\hline \multirow[t]{2}{*}{ Boscia albitrunca } & Capparaceae & Munkudi & Syphilis & 4 days (depends on the severity) \\
\hline & & & Chicken pox & 2 days \\
\hline Clerodendrum ternatum & Lamiaceae & Shanyu & Eczema & 1 - 7 day \\
\hline Colophospermum mopane & Fabaceae & Omusati & Swollen legs & One week \\
\hline \multirow[t]{2}{*}{ Combretum collinum } & Combretaceae & Mububu & Coughing & 1 week \\
\hline & & & Panaritium & 1 week \\
\hline \multirow[t]{3}{*}{ Combretum imberbe } & Combretaceae & Omukuku & Gonorrhea & 2 -7days \\
\hline & & & Fertility/impotent & 1 day \\
\hline & & & Male dysfunction & 1-4 day \\
\hline \multirow[t]{2}{*}{ Croton gratissimus } & Euphorbiaceae & Ongonyo & Tetanus & 2 - 3 days \\
\hline & & & Lightening burn & One day \\
\hline Cyperus papyrus & Cyperaceae & Onziku & Giving birth & 1 day \\
\hline Datura stramonium & Solanaceae & Egwitha & Mental illnesses & 2 - 3 days, up to 16 months \\
\hline Dicoma tomentosa & Asteraceae & Okalupulupu & Intestine cram & $1-3$ days, 4 - 5 Months \\
\hline \multirow[t]{2}{*}{ Diospyros lycoides } & Ebenaceae & Oshimumu & Bleeding & $1-4$ days \\
\hline & & & Higher fever & 1 day \\
\hline Diospyros mespiliformis & Ebenaceae & Omwandi & Male dysfunction & 1- 4 day \\
\hline \multirow[t]{3}{*}{ Dregia macrantha } & Apocynaceae & Ondhingulula & Male dysfunction & 1- 4 day \\
\hline & & & Easing birth & Few hours \\
\hline & & & Mental illnesses & 2 - 3 days, up to 16 months \\
\hline \multirow[t]{2}{*}{ Erythropheum africanum } & Erythroxylaceae & Mupako & Gonorrhea & 2 -7days \\
\hline & & & Mental illnesses & 2 - 3 days, up to 16 months \\
\hline Euclea divinorum & Ebenaceae & Omudime & Bleeding & $1-4$ days \\
\hline Euphorbia monteiroi & Euphorbiaceae & Oshilalanamawadi & Mental illnesses & 2 - 3 days, up to 16 months \\
\hline Ficus sycomorus & Moraceae & Omukwiyu & Dermatitis & 1 month \\
\hline Gloriosa virescens & Colchicaceae & Ompilu & Intestine cram & 1 -3 days, 4 - 5 Months \\
\hline Harpagophytum procumbens & Pedaliaceae & Ekakata & Epilepsy & 1 month \\
\hline Harpagophytum zeyheri & Pedaliaceae & Ekakata & Epilepsy & 1 month \\
\hline \multirow[t]{2}{*}{ Helinus intergrifolius } & Rhamnaceae & Murora & Leg pains & 2 -7days \\
\hline & & & Stroke & 2 weeks, $4-6$ months \\
\hline \multirow[t]{2}{*}{ Helinus spartoides } & Rhamnaceae & Omutiwoheva & Leg pains & 2 -7days \\
\hline & & & Stroke & 2 weeks, $4-6$ months \\
\hline Heliotropium sp. & Boraginaceae & Ohanauni & Inflammation & Vary \\
\hline \multirow[t]{2}{*}{ Kleinia longiflora } & Asteraceae & Elangelamwali & Mental illnesses & 2 - 3 days, up to 16 months \\
\hline & & & Colloid & Vary \\
\hline Kohautia angolensis & Rubiaceae & Omutingulula & Intestine cram & 1 -3 days, 4 - 5 Months \\
\hline Lonchocarpus nelsii & Fabaceae & Mupanda & Back pains & 2 days \\
\hline Peltophorum africanum & Fabaceae & Omupalala & Leg pains & 2 -7days \\
\hline Pergularia daemia & Apocynaceae & Eriko & Mental illnesses & 2 - 3 days, up to 16 months \\
\hline Plumbago zeylanica & Plumbaginaceae & Okadimeti & Bleeding & $1-4$ days \\
\hline \multirow[t]{3}{*}{ Pterocarpus angolensis } & Fabaceae & Uguva & Coughing & 1 week \\
\hline & & & Leg pains & 2 -7days \\
\hline & & & Bleeding & 1 - 4 days \\
\hline
\end{tabular}


Table 1 Medicinal plants used to cure various ailments in Oshikoto region, Namibia (Continued)

\begin{tabular}{|c|c|c|c|c|}
\hline Rhigozum brevispinosum & Bignoniaceae & Ngandu & Syphilis & 4 days (depends on the severity) \\
\hline Ricinus communis & Euphorbiaceae & Olumono & Epilepsy & 1 month \\
\hline Securidaca longepedunculata & Polygalaceae & Omudhiku & Stroke & 2 weeks, $4-6$ months \\
\hline Senna italic & Fabaceae & Okatundangu & Abscess & depends \\
\hline Spirostachys africana & Euphorbiaceae & Omuhongo & Leg pains & 2 -7days \\
\hline Strychnos cocculoides & Loganiaceae & Maguni & Culture bound syndrome & 2-3 Days \\
\hline Swartzia madagascariensis & Fabaceae & Omukonati & Bleeding & 1 - 4 days \\
\hline Terminalia sericea & Combretaceae & Omugolo & Leg pains & 2 -7days \\
\hline Tragia okanyua & Euphorbiaceae & Okalilifa & Generalised oedema & 4 - 5 months \\
\hline Unidentified & & Munzwe & Ear infection & 1 day \\
\hline Unidentified & & Xhangau & Diarrhoea & $2-3$ days \\
\hline Unidentified & & !hare & Abdomen pain & 2 days \\
\hline Unidentified & & Guturoa & Worms & 2 - 3 days \\
\hline Unidentified & & Okayekaathithi & Meningitis & Vary \\
\hline Unidentified & & Oshihangena & Barren & Vary \\
\hline Unidentified & & Onzingankelo & High Blood Pressure & Vary \\
\hline Unidentified & & okasisiti & Fatigue & 4-5 days \\
\hline Unidentified & & Oshihangena & Easing birth & Few hours \\
\hline Vangueria infausta & Rubiaceae & Oshimbu & Dermatitis & 1 month \\
\hline Vigna dinteri & Fabaceae & Muyimbo & Herpes & 1 year \\
\hline \multirow[t]{3}{*}{ Ximenia americanum } & Olacaceae & Kakukuru & Scoliosis & 1 week \\
\hline & & & Culture bound syndrome & 2-4 Days \\
\hline & & & Gonorrhea & 2 -7days \\
\hline \multirow[t]{3}{*}{ Ximenia caffra } & Olacaceae & Ompeke & Fertility/impotent & 1 day \\
\hline & & & Culture bound syndrome & 2-5 Days \\
\hline & & & Gonorrhea & 2 -7days \\
\hline Ziziphus mucronata & Rhamnaceae & Mukekete & Gonorrhea & 2 -7days \\
\hline
\end{tabular}

Teklehaymanot [19] who reported that the roots used in the preparations in both single and multiple treatment with $58 \%$ and $48 \%$ respectively. On the other hand; the results of this study are not in agreement with some other studies which had addressed that leaves was the most common used parts for the treatments $[32,33]$.

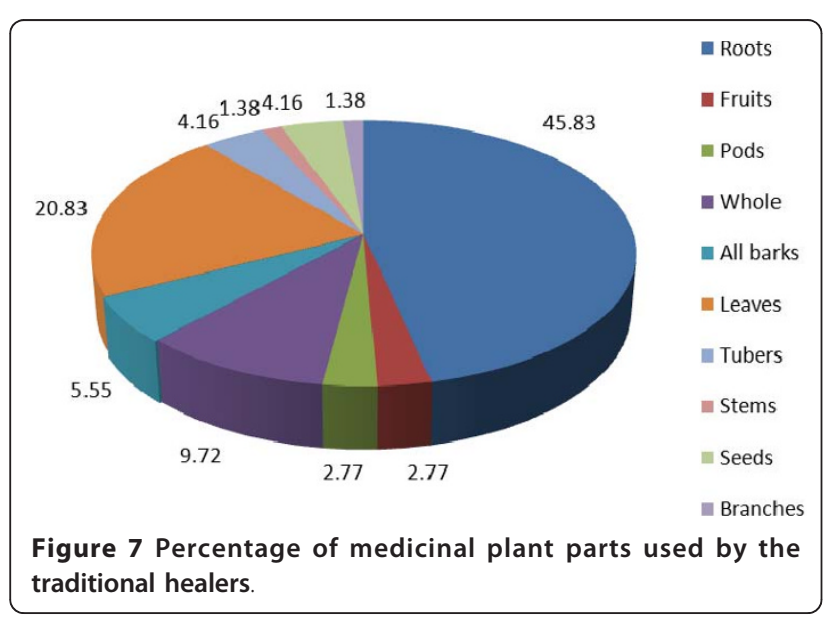

Regarding to the preparation method (fresh and dry) of used medicinal plants (Figure 8); it was found that $50 \%$ was used in both forms, then with $30 \%$ in fresh form and $20 \%$ for the dry form only. The traditional healers prescribed their treatment either on single plant use like the prescriptions for chicken pox, diarrhoea, ear

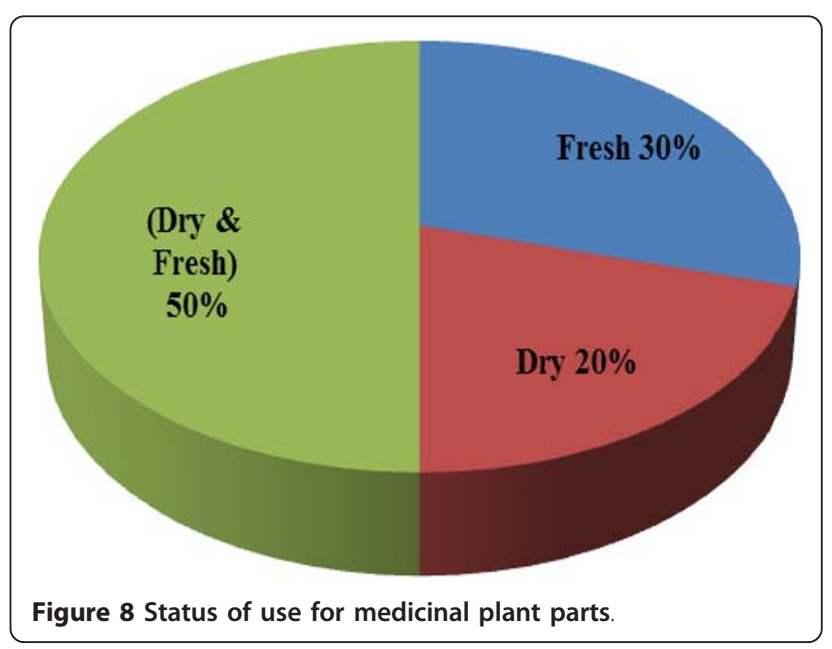


infection and headache, or using a combination of different parts as it was prescribed for leg pains, bleeding, stroke and tetanus (Table 1). Similar results were also reported in various studies conducted in India $[19,32,33]$. This agreement could help for ethnopharmacological selection of plants for future phytochemical and pharmacological study $[19,20]$.

\section{Life form and citied medicinal plants}

Regarding to the life form of the reported medicinal plants by the respondents; the study showed that trees ( 28 species) were found to be the most used plants (Figure 9) followed by herbs (15 species), shrubs (10 species) and climbers (4 species) in descending order. The most dominant families in the study were Fabaceae (9 species), Euphorbiaceae (5 species), Rhamnaceae, Combretaceae and Ebenaceae (3 species). Other families with low number are listed below: Olacaceae, Plumbaginaceae, Asteraceae, Rubiaceae, Apocynaceae, Asparagaceae and Pedaliaceae (2 species), other families which represented with only one species are represented in Figure 10.

In this study; 47 respondents reported 61 medicinal plants species that belonged to 25 families. The most cited plants mentioned by the respondents are: Pterocarpus angolensis, Ximenia americanum, Ximenia caffra and Combretum imberbe. The total number of plant species used by the traditional healers normally will be diminishing in supply. Some plant species that are becoming more difficult to obtain include Albizia brevifolia, Commiphora mollis, Commiphora glaucescens, Commiphora pyracanthoides, Elephantorhiza elephantina, Fockea angustifolia, Gardenia spatulifolia, Momordica balsamina, and Protea gaguedi. Protea gaguedi, which occurred naturally along the Okavango River in Namibia, is practically extinct [14] due to frequent field fires and the over-exploitation of the roots for medicinal purposes; however these species are still available in neighbouring countries.

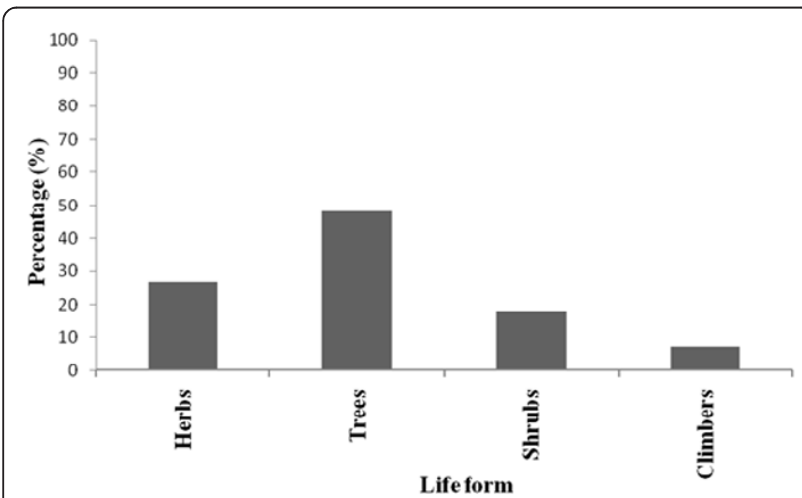

Figure 9 Percentage distributions of medicinal plant species according to the life form

\section{Informant consensus}

Table 2 shows the Informant consensus factor $\left(\mathrm{F}_{\mathrm{IC}}\right)$ for the different ailments treated by the traditional healers in Oshikoto region. The level of informants agreement was high for most ailment categories (mean FIC $=0.75$ ) and total consensus (FIC $=1.00)$ was even obtained for weakness and dizziness problems, snake bite, swelling and Cardiovascular problems (Table 2). Cough and cold category, as well as infection and inflammation showed relatively low levels of consensus $(\mathrm{FIC}=0.50)$. High $\mathrm{F}_{\mathrm{IC}}$ values indicating that the species traditionally used to treat these ailments are worth searching for bioactive compounds: Pergularia daemia, Colophospermum mopane and Tragia okanyua. These results are in agreement with Ignacimuthu et al [34] who reported that Pergularia daemia was used by tribes in Madurai district of Tamil Nadu, India for the treatment of headache. Pergularia daemia is found to be useful as anthelmintic, laxative, anti-pyretic, expectorant, and used in infantile diarrhoea [35]. The anti-inflammatory, anti-pyretic and analgesic activities of Pergularia daemia were reported also [36]. The plant was also found to possess anti-diabetic activity [37]. The proposed activities may be a result of the presence of flavonoid compounds; so the searching for bioactive compounds from this plant is very promising [35]. Fidelity level (FL) was calculated for medicinal plants which have been cited by four or more informants for being used against a given ailment. The following species: Euclea divinorum, Erythropheum africanum, Baphia massaiensis, Kohautia angolensis, Asparagus nelsii, Clerodendrum ternatum and Ricinus communis were the ones scoring the highest values (Table 3).

At present the different policy and legislative instruments in Namibia addressing intellectual property rights (IPR) which cover areas such as bio-trade of medicinal plants, plant genetic resources, access and benefit sharing (ABS) need harmonization. However, Namibia is a Signatory to Cites, which also lists a number of fauna and flora species to be protected, FAO Treaty on exchange of agricultural research. There exists a Patent Office under the Ministry of Trade and Industry, but the absence of a policy regarding IPR as well as limited capacity to deal with IPR issues is a concern. Namibia is a Signatory to the Convention on Biological Diversity (CBD) which includes among other the ABS Protocol, and this protocol was adopted in 2010 in Nagoya, Japan. In Namibia, the Ministry of Environment and Tourism is responsible for this protocol and they are also working on a draft policy for ABS in Namibia. According to Du Plessis; Namibia has had a draft bill on ABS since 2007, but because of technical reasons, the bill has not been finalized and enacted into law [38]. To conduct research and collect plants require a permit from the 


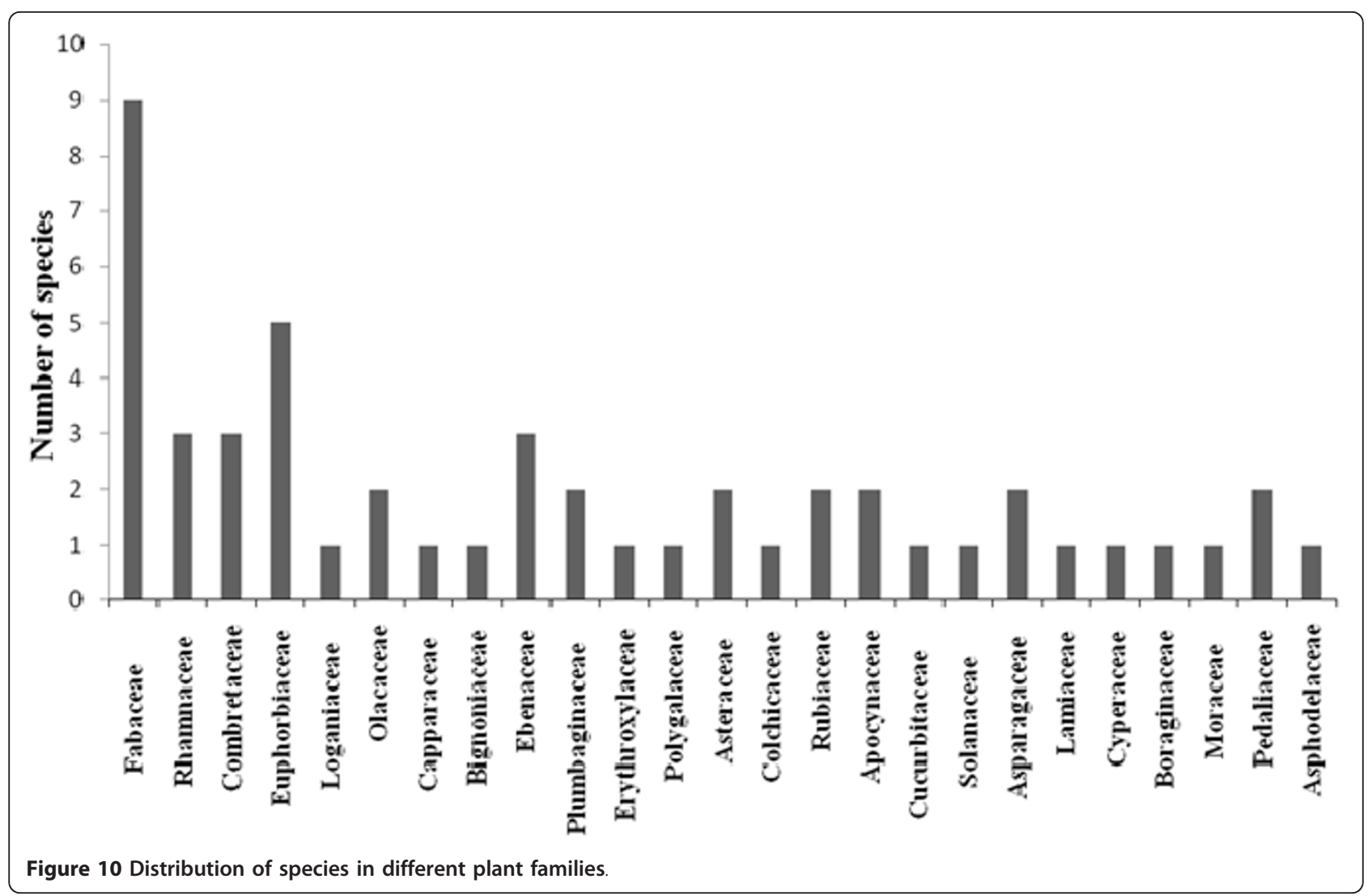

Table 2 Informant consensus factor $\left(F_{\text {IC }}\right)$ for different ailment categories

\begin{tabular}{llll}
\hline Ailment & $\begin{array}{l}\text { Number of } \\
\text { taxa (Nt) }\end{array}$ & $\begin{array}{l}\text { Number of use } \\
\text { reports (Nur) }\end{array}$ & $\mathbf{F}_{\mathbf{I C}}$ \\
\hline $\begin{array}{l}\text { Gastro-intestinal \& } \\
\text { Intestinal parasites }\end{array}$ & 8 & 21 & 0.65 \\
Fever and headache & 2 & 5 & 0.75 \\
Muscular-skeletal & 4 & 10 & 0.66 \\
problems & & & \\
Weakness and dizziness & 1 & 2 & 1.00 \\
Cuts and wounds & 5 & 19 & 0.77 \\
Cough and cold & 2 & 3 & 0.50 \\
Respiratory problems & 2 & 4 & 0.66 \\
Infectious \& Transmitted & 6 & 15 & 0.64 \\
diseases & & & \\
Cardiovascular problems & 1 & 2 & 1.00 \\
Impotence & 8 & 19 & 0.61 \\
Birth problems & 3 & 10 & 0.77 \\
Mental diseases & 6 & 26 & 0.80 \\
Skin infection & 7 & 25 & 0.75 \\
Snake bite & 1 & 2 & 1.00 \\
Swelling & 1 & 3 & 1.00 \\
Neurologic diseases & 8 & 21 & 0.65 \\
Infection and & 5 & 9 & 0.50 \\
Inflammation & & & \\
\hline
\end{tabular}

Ministry of Environment and Tourism. The Namibian Government has instituted the National Biodiversity Programme (NBF), the Indigenous Plant Task Team (IPTT), and the Interim Plant Bio-prospecting Council (IPBC), mandated by Cabinet to formulate policies and legislation to regulate the above mentioned issues [39]. More recently, an Industrial Property Protection Bill was drafted and is being discussed by the respective legislative house in the Namibian Parliament. The proposed Bill is silent on issues of Indigenous Knowledge. Nevertheless, Namibia remains a very active player on IKS the SADC level and is in the process of developing an IKS National policy. It is envisaged that the policy will strongly address issues related to IPR of indigenous people, provide clear guidelines and protocols and IK research and the economic utilization thereof. The collaborative research study between the Directorate of Research, Science and Technology in the Ministry of Education and the Multidisciplinary Research Centre at the University of Namibia, which started in 2008 on Indigenous Knowledge Systems (IKS), will contribute to the drafting of the policy to regulate and coordinate the IKS issues in particular related to Traditional Healing $(\mathrm{TH})$ and the use of knowledge generated from Indigenous Plants in Namibia. 
Table 3 Fidelity level (FL) values of medicinal plants cited by four or more informants for being used against a given ailment

\begin{tabular}{|c|c|c|c|c|}
\hline Medicinal plant & Local name & Therapeutic uses & Number of Informants & FL value (\%) \\
\hline Euclea divinorum & Omudime & Bleeding & 5 & 100.00 \\
\hline Erythropheum africanum & Mupako & Mental illnesses & 4 & 100.00 \\
\hline Baphia massaiensis & Omulyambambi & Fertility or impotence & 4 & 100.00 \\
\hline Kohautia angolensis & Omutingulula & Intestine cram & 8 & 100.00 \\
\hline Asparagus nelsii & Okawekamuthithi & Eczema & 8 & 100.00 \\
\hline Clerodendrum ternatum & Shanyu & Eczema & 5 & 100.00 \\
\hline Ricinus communis & Olumono & Epilepsy & 4 & 100.00 \\
\hline Unidentified & Xhangau & Diarrhoea & 4 & 100.00 \\
\hline Diospyros lycoides & Oshimumu & Bleeding, Worms & 6 & 83.33 \\
\hline Boscia albitrunc & Munkudi & Chicken pox, Syphilis & 4 & 75.00 \\
\hline Ximenia caffra & Ompeke & Gonorrhea, Culture bound syndrome, Fertility & 6 & 66.66 \\
\hline Pergularia daemia & Eriko & Mental illnesses, Fertility or impotent, Snake bite & 6 & 66.66 \\
\hline Dregia macrantha & Ondhingulula & Mental illnesses, Fertility or impotent, Erectile dysfunction & 8 & 62.50 \\
\hline Croton gratissimus & Ongonyo & Tetanus, Lightening burn & 5 & 60.00 \\
\hline Pterocarpus angolensis & Uguva & Leg pain, Coughing, Bleeding & 7 & 57.14 \\
\hline Acacia ataxacantha & Mukoro & Headache, Bleeding, Pneumonia & 7 & 57.14 \\
\hline Kleinia longiflora & Elangelamwali & Mental illnesses, Fertility or impotent, Colloid & 6 & 50.00 \\
\hline
\end{tabular}

Resolving of these issues is still at a primary phase because of the lack for national legislation relating to indigenous knowledge on indigenous plants. A Research, Science and Technology Act on this protocol was passed in 2004 to govern research activities and institutions in Namibia.

\section{Conclusions}

This study showed that the study area has plenty of medicinal plants to treat a wide spectrum of human ailments. Many people in the study areas of the Oshikoto region are still depending on medicinal plants, at least for the treatment of some simple diseases such as, cold, cough, fever, headache, poison bites, skin diseases and tooth infections. It is necessary to acquire and preserve this traditional system of medicine by proper documentation and identification of specimens. A nationwide database is in the process of being established by collecting all conceivable IKS plant-based nationwide medicinal therapeutic data as currently applied by traditional healers. This traditional knowledge on the indigenous uses of the medicinal plants could boost new innovations in the pharmaceutical industry and have many beneficial applications such as new medicinal trails for some diseases like: malaria, Tuberculosis and AIDS, of which will develop the health care sector in Namibia.

\section{Acknowledgements}

The authors would like to thank the Ministry of Education through the Directorate of Research Science and Technology (DRST) represented by the Director Mr. A. Van Kent and the deputy director Mr. John Sifani for the financial assistance. We appreciate the support we received from all the regional councilors in the ten constituencies of Oshikoto region especially the Governor of the Oshikoto Region Honorable Penda Ya Ndakomolo and the Councilor of Onayena Constituency, in the same region Hon Max Nekongo. We would like to acknowledge the willingness and openness of the traditional healers interviewed in this study and the enumerators for making it possible for us to speak to them and learn more from their experience. We thank Ms. F. Kangombe, Biota researcher at the National Botanical Research Institute (NBRI), Windhoek; for her assistance in providing the botanical names of the medicinal plants.

\section{Author details}

'Science, Technology and Innovation Division, Multidisciplinary Research Centre- University of Namibia, Private Bag 13301, Windhoek, Namibia. ${ }^{2}$ Social Sciences Division, Multidisciplinary Research Centre-University of Namibia, Private Bag 13301, Windhoek, Namibia.

\section{Authors' contributions}

MS had interviewed the traditional healers in Oshikoto region; he has analyzed and drafted the report on the medicinal plant use by traditional healers. KM designed the questionnaire, and reviewed the manuscript. HMA led the research project and also reviewed the manuscript. AC has written the article, organized the compiled research data and carried out the statistical analysis. All authors read and approved the final manuscript.

\section{Competing interests}

The authors declare that they have no competing interests.

Received: 9 June 2010 Accepted: 9 March 2011 Published: 9 March 2011

\section{References}

1. WHO: The promotion and development of traditional medicine. Report of a World Health Organization Meeting. Technical Report Series 622 Geneva; 1978.

2. Matsheta MS, Mulaudzi FM: The Perceptions of Traditional Healers of Cervical Cancer Care at Ga Mothapo Village in Limpopo Province. Indilinga: African J of Indigenous Knowledge Systems 2008, 7:103-116.

3. Rinne E: Water and Healing - Experiences from the Traditional Healers in lle-Ife, Nigeria. Nordic J of African Studies 2001, 10:41-65.

4. Pei SJ: Ethnobotanical approaches of traditional medicine srudies: Some experiences from Asia. Pharmaceutical Biology 2001, 39:74-79.

5. Muthu C, Ayyanar M, Raja N, Ignacimuthu S: Medicinal plants used by traditional healers in Kancheepuram District of Tamil Nadu, India. Journal of Ethnobiology and Ethnomedicine 2006, 2:43. 
6. Giday M, Asfaw Z, Woldu Z, Teklehaymanot T: Medicinal plant knowledge of the Bench ethnic group of Ethiopia: an ethnobotanical investigation. Journal of Ethnobiology and Ethnomedicine 2009, 5:34

7. Uprety $Y$, Asselin H, Boon EK, Yadav S, Shrestha KK: Indigenous use and bio-efficacy of medicinal plants in the Rasuwa District, Central Nepal. Journal of Ethnobiology and Ethnomedicine 2010, 6:3, 2010.

8. David JS: An ethnobotanical survey of medicinal plants in Babungo, Northwest Region, Cameroon. Journal of Ethnobiology and Ethnomedicine 2010, 6:8.

9. Marshall NT: Searching for a cure: Conservation of medicinal wildlife resources in eastern and southern Africa. TRAFFIC East/southern Africa \& TRAFFIC International, Cambridge; 1998.

10. Mapaure I, Hatuikulipi T: Namibia's Indigenous Knowledge System: IKS Literature Review Report on the Use of Plants for Medicinal and Other Purposes by Local Communities in Namibia. University of Namibia, Windhoek; 2008

11. LeBeau D: Dealing with disorder: traditional and western medicine in Katutura (Namibia). Rüdiger Köppe Verlag, Köln, Germany; 2003.

12. National Herbarium of Namibia (WIND): SPMNDB Database. WIND, National Botanical Research Institute, MAWF, Windhoek; 2007, 2007.

13. Lumpkin TW: Traditional healers and community use of traditional medicine in Namibia. Ministry of Health \& Social Services and UNICEF, Windhoek; 1994.

14. Cunningham AB: The role of ethnobotany and indigenous knowledge in conservation of plant genetic resources. Dinteria 1992, 23:119-131.

15. Pfeiffer JM, Butz RJ: Assessing cultural and ecological variation in ethnobiological research: the importance of gender. Journal of Ethnobiology 2005, 25:240-278.

16. Heinrich M, Ankli A, Frei B, Weimann C, Sticher O: Medicinal plants in Mexico: Healers' consensus and cultural importance. Social Science and Medicine 1998, 47:1859-1871.

17. Canales M, Hernandez T, Caballero J, Romo de Vivar A, Avila G, Duran A, Lira R: Informant consensus factor and antibacterial activity of the medicinal plants used by the people of San Rafael Coxcatlan, Puebla, Mexico. Journal of Ethnopharmacology 2005, 97:429-439.

18. Alexiades MN, Sheldon JW: Selected Guidelines for Ethnobotanical Research: A Field Manual. Advances in Economic Botany, vol. 10 The New York Botanical Garden, Bronx, New York; 1996.

19. Teklehaymanot T: Ethnobotanical study of knowledge and medicinal plants use by the people in Dek Island in Ethiopia. Journal of Ethnopharmacology 2009, 124:69-78.

20. Trotter RT, Logan MH: Informants consensus: a new approach for identifying potentially effective medicinal plants. In Plants in Indigenous Medicine and Diet. Edited by: Etkin NL. Redgrave Publishing Company, Bedford Hill, NY; 1986:91-112.

21. Shapi M, Matengu K, Mu Ashekele H: Indigenous Knowledge System Pilot Study - Oshikoto Region. Multidisciplinary Research Centre, University of Namibia, Windhoek; 2009.

22. Obi SN: Extramarital Sexual Activity among Infertile Women in Southeast Nigeria. The Journal of Obstetrics and Gynecology of India 2006, 56:72-75.

23. Bishaw M: Attitudes of modern and traditional medical practitioners toward cooperation. Ethiopian Medical Journal 1990, 28:63-72.

24. Balick MJ, Cox PA: Plants, People and Culture: The Science of Ethnobotany. The Scientific American Library, New York; 1996.

25. Azaizeh H, Fulder S, Khalil K, Said O: Ethnomedicinal knowledge of local Arab practitioners in the Middle East Region. Fitoterapia 2003, 74:98-108, 2003.

26. Leffers A: Gemsbok Bean \& Kalahari Truffle: Traditional plant use by Jul'hoansi in North-Eastern Namibia. Gamsberg Macmillan, Windhoek; 2003.

27. Busia K: Medical provision in Africa - Past and present. Phytotherapy Research 2005, 19:919-923.

28. Tapsoba H, Deschamps JP: Use of medicinal plants for the treatment of oral diseases in Burkina Faso. Journal of Ethnopharmacology 2006, 104:68-78.

29. Saikia AP, Ryakala VK, Sharma P, Goswami P, Bora U: Ethnobotany of medicinal plants used by Assamese people for various skin ailments and cosmetics. Journal of Ethnopharmacology 2006, 106:149-157.

30. Fawole OA, Finnie JF, Van Staden J: Antimicrobial activity and mutagenic effects of twelve traditional medicinal plants used to treat ailments related to the gastro-intestinal tract in South Africa. South African Journal of Botany 2009, 75:356-362.

31. Van Wyk BE, de Wet $H$, Van Heerden FR: An ethnobotanical survey of medicinal plants in the southeastern Karoo, South Africa. South African Journal of Botany 2008, 74:696-704.

32. Upadhyay PB, Roy S, Kumar A: Traditional uses of medicinal plants among the rural communities of Churu district in the Thar Desert India. Journal of Ethnopharmacology 2007, 113:387-399.

33. Panghal M, Arya V, Yadav S, Kumar S, Yadav JP: Indigenous knowledge of medicinal plants used by Saperas community of Khetawas, Jhajjar District, Haryana, India. Journal of Ethnobiology and Ethnomedicine 2010, 6:4.

34. Ignacimuthu S, Ayyanar M, Sankarasivaraman K: Ethnobotanical investigations among tribes in Madurai district of Tamil Nadu, India. Journal of Ethnobiology and Ethnomedicine 2006, 2:25.

35. Sureshkumar SV, Mishra SH: Hepatoprotective effect of extracts from Pergularia daemia Forsk. Journal of Ethnopharmacology 2006, 107:164-168.

36. Sathish CJ, Sharma RA, Jain R, Mascalo N, Capasso F, Vijayvergia R, Mittal C: Ethnopharmacological evaluation of Pergularia daemia (Forsk.) Chiov. Phytotherapy Research 1998, 12:378-380.

37. Wahi AK, Ravi J, Hemalatha S, Singh PN: Anti-diabetic activity of Daemia extensa. Journal of Natural Remedies 2002, 2:80-83.

38. Du Plessis P: Indigenous knowledge and bio-trade. Presentation at the National Biosciences Forum and validation of traditional medicines workshop, Safari Hotel, Windhoek; 2007.

39. Chinsembu KC, Hedimbi M: An ethnobotanical survey of plants used to manage HIV/AIDS opportunistic infections in Katima Mulilo, Caprivi region, Namibia. Journal of Ethnobiology and Ethnomedicine 2010, 6:25.

doi:10.1186/1746-4269-7-10

Cite this article as: Cheikhyoussef et al: Ethnobotanical study of indigenous knowledge on medicinal plant use by traditional healers in Oshikoto region, Namibia. Journal of Ethnobiology and Ethnomedicine 2011 7:10

\section{Submit your next manuscript to BioMed Central and take full advantage of:}

- Convenient online submission

- Thorough peer review

- No space constraints or color figure charges

- Immediate publication on acceptance

- Inclusion in PubMed, CAS, Scopus and Google Scholar

- Research which is freely available for redistribution

Submit your manuscript at www.biomedcentral.com/submit
Ciomed Central 